\title{
Samantha Adams Festschrift: Coming of Age-Samantha Adams's Career at Erasmus University Rotterdam
}

\author{
Jos Aarts $^{1}$ \\ 1 Erasmus School of Health Policy \& Management, Erasmus University \\ Rotterdam, Rotterdam, The Netherlands
}

Appl Clin Inform 2018;9:493-495.

In 2000, Marc Berg placed a call to Samantha Adams who was then back home in North Carolina after obtaining an MA in Science, Technology and Society Studies from Maastricht University in 1999. He had a job offer for a PhD studentship to study the reliability of information on the Internet and social media. He thought also that Sam having a boyfriend in the Netherlands would be a big incentive. She returned to the Netherlands to make it her home and never went back.

Samantha Adams spent most of her professional life at Erasmus University Rotterdam in the Erasmus School of Health Policy \& Management. In my tribute to her, I will describe her research, her contribution to education, and my personal perspective.

Health informatics research was until the turn of the century focused on technology and use by professionals. The advent of Internet meant a push forward for democratization of technology and engagement of patients. ${ }^{1}$ Soon, a large number of health and medical Web sites were published that patients could access. Web sites were not only published by respected organizations, but by anyone with basic skills to create them. Concerns were raised about the quality of information, and a code of conduct for publishing information was developed by the nonprofit organization Health On the Net. ${ }^{2}$ In this context, Sam started her work on information reliability on the Web. Perhaps this concern can be construed as paternalistic; by having guidelines for information quality, consumers and patients can be nudged to go to the right place. Adams argues that "one comprehensive reliability model to which all sites and licensers must adhere is not only inherently doomed to fail, but it is also deeply undesirable." 3 Such analysis is characteristic of Sam. She deconstructs the notion of reliability by looking at the history of licensing of books. Contrary to common belief that the population needs to be protected from erroneous or false health information, she argues that a gate-keeping regime will stifle diversity of use on the Internet and therefore be detrimental. Moreover, in an ethnographic study of patients seeking health information on the Net she shows how patients do not use national portals, icons, or a standard checklist, but rather elaborate personal judgments of the adequacy of information for their own purposes. ${ }^{4}$ These and other studies of information reliability resulted in her doctoral thesis, which she defended in 2006. ${ }^{5}$

After graduation, Sam became assistant professor in the department of Health Care Governance of the Erasmus School of Health Policy \& Management. She expanded her research to social media in general and the role of patient and consumers. In her research, she was very precise about the quality of qualitative research and good writing. Qualitative research should be guided by theory, both in framing research questions and analyzing and interpreting results. She brought that perspective to teaching research methods in the bachelor of health sciences program and health care management program at Erasmus University Rotterdam. She was instrumental in introducing a writing skills course in the bachelor program in preparation for thesis work. She was equally at home in English and Dutch. During her time at Erasmus, she supervised thesis work of many bachelor and master degree students. She consistently emphasized the necessity of clear writing. From 2009 till 2011, Sam was coordinator of the bachelor undergraduate degree program of health sciences and was responsible for efforts to reduce student dropout and course efficacy.

Although Sam Adams retained her focus on patient-centered eHealth research, she made excursions to other studies, where consumers played a key role. For example, she took part in a study of mystery guests as "lay inspectors" to improve the efficacy and effectiveness of health inspectorates as regulators or governing agents. ${ }^{6}$ Sam broadened her research line from constructing reliability of health Web sites to patient-centered
Address for correspondence

Jos Aarts, PhD, FACMI, Erasmus

School of Health Policy \&

Management, Erasmus University

Rotterdam, P. O. Box 1738,

Rotterdam 3000 DR,

The Netherlands

(e-mail: aarts@eshpm.eur.nl). (c) 2018 Georg Thieme Verlag KG Stuttgart · New York
DOI https://doi.org/

$10.1055 / \mathrm{s}-0038-1656523$.

ISSN 1869-0327. 
care and social media and included themes such as personalized Web-based health information, blogging, and crowdsourcing. Of note was her study of the first Twitter surgery in the Netherlands, in which she considered ethical issues of using social media for health-related purposes. ${ }^{7}$ From her perspective of patient-centered care Sam took part in a study program of chronic disease management. ${ }^{8}$ She successfully supervised two Erasmus PhD students, Bethany Hipple Walters and Femke Vennik, who obtained their doctorate degrees in 2015 and 2016, respectively. Unfortunately, she was not able to complete her supervision of her last $\mathrm{PhD}$ student Marcello Aspria, because of her untimely demise. In 2014 she moved to the Tilburg Institute of Law and Technology of Tilburg University.

Sam and I were colleagues for 14 years at Erasmus University. Our research did not overlap; I addressed the impact of information technology on professional practices and found my niche in medication safety, and for Sam it was patients and consumers in an emerging networked society. However, we shared an interest in things American, politics, history, and cats. We bonded also, in that since the early 2000s we were both working on our PhD thesis under the supervision of Marc Berg and shared our excitement about successes and frustrations about setbacks. At my suggestion, we traveled together to the 2002 Annual Symposium of the American Medical Informatics Association. Sam was part of the keynote panel at the symposium, where she, Madhu Reddy, Joan Ash, and I reported on the first sociotechnical conference Information Technology in Healthcare held in Rotterdam in September 2001. ${ }^{9}$ Sam was very closely involved with the sociotechnical conferences that followed. Sam found in the American Medical Informatics Association (AMIA) an intellectual and academic home and made friends almost immediately. Sam participated in the Student Working Group, People and Organizational Issues Working Group, and was a member and chair of the Diana Forsythe Award Committee and the AMIA Ethics Committee. Elsewhere in this issue, you will find papers about Sam's engagement with activities in AMIA. We have attended together since then many AMIA conferences. In 2011, we traveled together to North Carolina to explore scientific collaboration with our colleague Eric Eisenstein at Duke University and Sam was very proud to show her alma mater. We actually collaborated not in concrete research projects, but at the meta-level by our shared experience at Erasmus University and AMIA. Sam was very direct in her communication and could be quite candid, but it was essential to cementing a relationship as academic professionals and friends. And we always spoke Dutch to each other. I saw her grow as a person determined to set her own research agenda. She came as a junior researcher and in 2014 she was ready to make the next move on the academic ladder. Actually, when Sam was in Tilburg, we collaborated formally for the first time on a research proposal about patient privacy and cybersecurity and submitted it to the National Science Foundation; despite good reviews it was not funded. Dr. Samantha Adams was a great researcher and teacher, and a fine person. I miss her sorely, but my feelings pale compared with those of her daughter Jadzia and husband Patrick.
During her tenure at Erasmus University, Sam wrote 30 papers, which are all listed below. They show the quality and diversity of her scientific work. ${ }^{3,4,6,8,10-32}$

\section{References}

1 Ferdinand P. The Internet, democracy and democratization. Democratization 2000;7(01):1-17

2 Boyer C, Selby M, Scherrer JR, Appel RD. The Health On the Net Code of Conduct for medical and health Websites. Comput Biol Med 1998;28(05):603-610

3 Adams SA, Berg M. The nature of the Net: constructing reliability of health information on the Web. Inf Technol People 2004;17 (02):150-170

4 Adams S, de Bont A, Berg M. Looking for answers, constructing reliability: an exploration into how Dutch patients check webbased medical information. Int J Med Inform 2006;75(01):66-72

5 Adams SA. Under Construction: Reviewing and Producing Information Reliability on the Web [PhD thesis]. Rotterdam: Erasmus University Rotterdam; 2006. Available at: http://handle.net/1765/ 7841

6 Adams SA, Paul KT, Ketelaars C, Robben P. The use of mystery guests by the Dutch Health Inspectorate: results of a pilot study in long-term intramural elderly care. Health Policy 2015;119(06): 821-830

7 Adams SA, Van Veghel D, Dekker L. Developing a research agenda on ethical issues related to using social media in healthcare. Camb Q Healthc Ethics 2015;24(03):293-302

8 Cramm JM, Adams SA, Walters BH, et al. The role of disease management programs in the health behavior of chronically ill patients. Patient Educ Couns 2014;95(01):137-142

9 Berg M, Aarts J, van der Lei J. ICT in health care: sociotechnical approaches. Methods Inf Med 2003;42(04):297-301

10 Adams S. Assessment strategies: how patients cope with the diverse quality levels of websites when searching for health information. AMIA Annu Symp Proc 2003:774

11 Adams SA, De Bont AA. Notions of reliability: considering the importance of difference in guiding patients to health care Web sites. Methods Inf Med 2003;42(04):307-312

12 Adams SA. Using blogging tools to help individuals record their experiences: an exploration and review of two commercial web applications in the Netherlands. Stud Health Technol Inform 2007;130:193-203

13 Adams S, de Bont $\mathrm{A}$. Information Rx: prescribing good consumerism and responsible citizenship. Health Care Anal 2007;15(04): 273-290

14 Adams SA, de Bont AA. More than just a mouse click: research into work practices behind the assignment of medical trust marks on the World Wide Web. Int J Med Inform 2007;76 (Suppl 1):S14-S20

15 Adams SA. Blog-based applications and health information: two case studies that illustrate important questions for Consumer Health Informatics (CHI) research. Int J Med Inform 2010;79(06):e89-e96

16 Adams SA, Bal R. Practicing reliability reconstructing traditional boundaries in the gray areas of health information review on the web. Sci Technol Human Values 2009;34(01):34-54

17 Adams SA. Revisiting the online health information reliability debate in the wake of "web 2.0": an inter-disciplinary literature and website review. Int J Med Inform 2010;79(06):391-400

18 Adams SA. Use of "serious health games" in health care: a review. Stud Health Technol Inform 2010;157:160-166

19 Adams SA. Sourcing the crowd for health services improvement: The reflexive patient and "share-your-experience" websites. Soc Sci Med 2011;72(07):1069-1076

20 Niazkhani Z, Pirnejad H, Aarts J, Adams S, Bal R. Reporting qualitative research in health informatics: REQ-HI recommendations. Stud Health Technol Inform 2011;169:877-881 
21 Walters BH, Adams SA, Nieboer AP, Bal R. Disease management projects and the Chronic Care Model in action: baseline qualitative research. BMC Health Serv Res 2012;12:114

22 Adams SA. Using patient-reported experiences for pharmacovigilance? Stud Health Technol Inform 2013;194:63-68

23 Adams SA. Post-panoptic surveillance through healthcare rating sites. Inf Commun Soc 2013;16(02):215-235

24 Adams SA, van de Bovenkamp H, Robben P. Including citizens in institutional reviews: expectations and experiences from the Dutch Healthcare Inspectorate. Health Expect 2015;18(05):1463-1473

25 Cramm JM, Tsiachristas A, Walters BH, et al. The management of cardiovascular disease in the Netherlands: analysis of different programmes. Int J Integr Care 2013;13:e028

26 Maresca D, Adams S, Maresca B, van der Steen AF. Mapping intravascular ultrasound controversies in interventional cardiology practice. PLoS One 2014;9(05):e97215

27 Tsiachristas A, Waters BH, Adams SA, Bal R, Mölken MP. Identifying and explaining the variability in development and implemen- tation costs of disease management programs in the Netherlands. BMC Health Serv Res 2014;14:518

28 Vennik FD, Adams SA, Faber MJ, Putters K. Expert and experiential knowledge in the same place: patients' experiences with online communities connecting patients and health professionals. Patient Educ Couns 2014;95(02):265-270

29 van Kruijssen V, van Staa A, Dwarswaard J, In 't Veen JC, Mennema $B$, Adams SA. Use of online self-management diaries in asthma and COPD: a qualitative study of subjects' and professionals' perceptions and behaviors. Respir Care 2015;60(08):1146-1156

30 Vennik FD, Adams SA, Putters K. Scripting the active patient in online health communities. J Assist Technol 2015;9(02):86-99

31 Aspria M, de Mul M, Adams SA, Bal R. Of blooming flowers and multiple sockets: the role of metaphors in the politics of infrastructural work. Sci Technol Stud 2016;29(03):68-87

32 Hipple Walters B, Adams S, Broer T, Bal R. Proud2Bme: exploratory research on care and control in young women's online eating disorder narratives. Health (London) 2016;20(03):220-241 